\title{
APPLICABILITY OF CITYGREEN URBAN ECOSYSTEM ANALYSIS SOFTWARE TO A DENSELY BUILT URBAN NEIGHBORHOOD ${ }^{1}$
}

\author{
Travis Longcore ${ }^{2}$ \\ Center for Sustainable Cities \\ Department of Geography \\ University of Southern California
}

\author{
Christina Li and John P. Wilson \\ GIS Research Laboratory, Department of Geography \\ University of Southern California
}

\begin{abstract}
In efforts to increase greenspace in cities, planners have relied on a series of arguments about the benefits of parks and other greenspace, including their economic value. The commercially available software program, CITYgreen 4.0, an extension of ArcView, calculates economic values for this purpose. The software evaluates the benefits of trees and other landscape features for energy use, stormwater runoff, air pollution, carbon sequestration, and wildlife habitat. While many examples are available of the use of CITYgreen in suburban morphologies, we set out to evaluate the applicability of CITYgreen for assessing these effects in a densely populated urban neighborhood. We inventoried 146 acres of urban land uses (commercial, residential, and institutional) in a Los Angeles neighborhood. CITYgreen does not calculate energy savings for structures larger than single-family residences, reducing its utility in densely built urban environments. The stormwater runoff reduction module works well when the field data themes were clipped so that the highest canopy (i.e., trees, shrubs, grass, or impermeable surface but no combination thereof) was recorded in every part of the study area. Carbon sequestration and air pollution removal modules worked well, but do not incorporate the best available science. Wildlife analysis falls short of its potential, given the extensive field data collected to use the program. [Key words: urban ecosystem analysis, GIS, urban forestry.]
\end{abstract}

\section{INTRODUCTION}

In efforts to increase the amount of greenspace in urban areas, planners have always relied on a series of arguments about the benefits of parks and other greenspace (Cranz, 1983). These arguments have remained relatively constant since the turn of the 20th century: parks are good for the health of urban residents; parks help socialize the urban citizenry; parks provide environmental benefits to the urban region (Cranz, 1983; Harnik, 2000). The technology of measurement has improved greatly during the past hundred

\footnotetext{
${ }^{1}$ This article was prepared as part of the research project "Toward a Sustainable Los Angeles: A Nature's Services Approach," funded by the John Randolph Haynes and Dora Haynes Foundation.

${ }^{2}$ Correspondence concerning this article should be addressed to Travis Longcore, Department of Geography, University of Southern California, 927 Hellman Way, PIC 200A, Los Angeles, CA 90089-0027; telephone: 213-821-1310; fax: 213-831-1328; e-mail: longcore@usc.edu
} 
years, and along with it the advent of cost-benefit analysis has demanded more measurement and quantification. One of the recent incarnations of the argument for trees and greenspace, both in cities and on a global scale, has been investigation into the economic value of "nature's services" (Costanza et al., 1997; Daily, 1997; Tyrvainen and Miettinen, 2000). One provocative report even identifies "money" as "the new face of ecology" (Tuma, 2001).

The scope of what is viewed as benefits and our ability to measure benefits have both increased since early planners called for the preservation of watershed management areas. Not only is reduced runoff quantified, but also reduced urban heat island effects, decreased cooling costs, pollution removal, and (a benefit recognized in the era of purported anthropogenic climate change) carbon sequestration (Nowak and McPherson, 1993; McPherson et al., 1994). Translating the functions of ecological, hydrological, and other environmental processes into economic values is an increasing phenomenon. Ecosystem services are valued at between \$16-54 trillion per year in the United States, and the value of honeybee pollination to agriculture in Europe alone was estimated to be worth $\$ 100$ billion in 1989 (Costanza et al., 1997; Daily, 1997). On a smaller scale, urban forests have been analyzed for their beneficial functions, and environmental benefits have been converted into economic values (Akbari et al., 1993; Nowak, 1994a, 1994b).

The U.S.-based nonprofit organization American Forests has become a leader in the popularization of this cost-benefit approach to inform land use planning. American Forests has developed a GIS based tool to calculate the economic benefits of urban forests (CITYgreen; this paper refers to version 4.0). This tool has been applied to create estimates of the economic value of forest cover in cities across the United States, and has attracted significant media attention (Miller, 1995; American Forests, 1998, 1999, 2000a; Lang, 1998; Pacific Meridian Resources, 2000). CITYgreen incorporates basic research conducted predominantly by the U.S. Forest Service (Nowak and McPherson, 1993; McPherson et al., 1994, 1999; Nowak, 1994a, 1994b; McPherson, 1997) and Lawrence Livermore Laboratory (Akbari et al., 1993, 1999).

CITYgreen is promoted as a tool for influencing public policy about urban greenspace, particularly trees (American Forests, 2000a). For the policy recommendations derived from the program to be relevant and effective two conditions must be met. The physical science used to calculate ecosystem processes must be sound and the conversion to economic terms must be reasonable. Furthermore, as a tool designed for "urban ecosystem analysis," CITYgreen should be applicable to all categories of urban morphology from suburban neighborhoods to inner cities. In this paper we review the success of the CITYgreen program in achieving the first of these conditions, especially as applied to longstanding and densely populated inner-city neighborhoods.

The remainder of this paper is divided into four sections. The next section reviews the history of nature's services analysis and the scientific principles incorporated in CITYgreen. This review is followed by a description of the methods and data that we used to deploy CITYgreen in the Vermont/Western study area. The largest section is devoted to an in-depth discussion of the capabilities and limitations of the CITYgreen program; this assessment is guided by our knowledge of the science as well as our experience in deploying this tool in our study area. The final section offers some conclusions and ideas for future work. 


\section{SCIENTIFIC BASIS FOR CITYGREEN MODULES}

The components of CITYgreen are derived from basic research conducted during the last several decades. For example, the stormwater analysis module is an adaptation of TR-55, a well-known and widely used hydrology model for urban watersheds developed by the U.S. Soil Conservation Service (now the Natural Resource Conservation Service), that was originally published in 1986 (Soil Conservation Service, 1986). The formulas and relationships incorporated in the TR-55 model are based on a series of research projects conducted in various parts of the United States in the 1960s and 1970s. The module is still widely used by engineering firms, soil conservation districts, and water management districts to evaluate the effects of land cover/land use changes and conservation practices on stormwater runoff volume, time of concentration, and peak flow for a study area.

The energy conservation model is based on research at Lawrence Livermore Laboratory and by the USDA's Forest Service (Huang et al., 1987; McPherson, 1994), and the air pollution model is largely based on studies by David Nowak (Nowak, 1994a; Nowak and Crane, 2000), which built on previous scholarship (Baldocchi, 1988). Carbon sequestration is modeled based on analyses by Nowak and Rowan Rowntree (Rowntree and Nowak, 1991).

The most comprehensive work on the benefits of urban forests was the Chicago Urban Climate Project, completed at the request of Mayor Daley by members of the USDA's Forest Service (McPherson, 1994). The comprehensive report of this project presents methodology and results for the influence of urban forests on wind, temperature, air pollution, carbon dioxide, cooling costs, and water exchange. Subsequently, personnel from the Chicago project have implemented parts of the analysis for other cities and regions (e.g. McPherson, 1997; McPherson et al., 1999).

Another area of urban climatological research has been the effect of roof color on cooling costs, conducted at UC Berkeley's Lawrence Livermore Laboratory (Akbari et al., 1993; Taha, 1996). While not within the direct scope of American Forest's interest in trees, a module on energy consequences of roof albedo is included in CITYgreen (American Forests, 2000a).

Since American Forests assembled the urban forestry work with the urban hydrology model in a geographic information system environment to create CITYgreen, the use of these models to inform policy debates has increased tremendously (Miller, 1995; American Forests, 1998, 1999, 2000b; Pacific Meridian Resources, 2000). These studies take a two-part approach, with both regional and local analyses. The regional analysis uses remotely sensed data to track forest cover over time in a region, showing change in the urban forest. The second involves local analysis of specific sites for environmental benefits of trees and open space, which are then extrapolated to entire regions. The CITYgreen instructions do not advise that these sites be chosen randomly. Extrapolation to the region is therefore problematic, suffering from a biased sample. The studies are often commissioned by local jurisdictions and completed by American Forests, or conducted by consultants using a similar format as the American Forest reports. We present a brief summary of our own deployment of the local analysis functions of CITYgreen, and then turn to our assessment of the capabilities and limitations of the program. 


\section{CASE STUDY}

The Vermont/Western Transportation Oriented District of Los Angeles is a neighborhood with high-density residential occupation, boulevard commercial areas, and a number of institutional uses (schools and hospitals; Fig. 1). In this 1,384-acre area, there are approximately 50,000 residents in 19,500 housing units. Residential density, at 36 residents per acre, is three times higher than the citywide average. The study area was divided into three subareas to allow for a geographically stratified sampling scheme (Table 1). Within each of these three areas, study sites were chosen to represent three land-use types: residential, institutional (e.g., public schools), and boulevard commercial. The nine study sites ranged from 6.5 acres to 21.4 acres (Table 1). One large institutional site was split to create a tenth site. Sites followed obvious boundaries to encompass single land uses.

During late 2000 and early 2001, we conducted field surveys at the ten subsites within the study area. All features (trees, shrubbery, grass, buildings, and paved surfaces) were mapped and data were collected about each tree. The total area surveyed was 146 acres, which included 1,890 trees. Land use was highly correlated with cover variables (Table 1). Institutional and residential sites had significantly more tree and grass cover than boulevard commercial areas. Percentage cover of buildings was not significantly different among all land use types, ranging from $25.5 \%$ to $33.3 \%$, and average percentage paved area ranged from $45.0 \%$ in residential areas to $65.9 \%$ in boulevard commercial areas. The results from our implementation of CITYgreen are used to identify the capabilities and limitations of the software in the discussion that follows.

\section{CAPABILILITIES AND LIMITATIONS OF CITYGREEN PROGRAM}

CITYgreen is a collection of models that calculate the benefits of trees and greenspace, based on a geographic representation of a study area. There are five separate models (air pollution removal, carbon sequestration/storage, stormwater runoff, energy conservation, cool roofs) and one database used to represent high and low wildlife value as noted in the previous section. In addition, a separate model projects tree growth based on current conditions.

\section{Air Pollution Removal}

This model consists of two parts: (1) estimation of the concentration of air pollution in the study area, and (2) calculation of the rate of pollution removal and total pollution removed. Pollution removal is calculated by multiplying the rate of deposition by the surface area of leaves and the amount of time leaves are present and exposed to pollution. The pollutant flux $\left(\mathrm{g} / \mathrm{cm}^{2} / \mathrm{sec}\right)$ equals the product of the pollutant velocity and its concentration (Nowak, 1994b). Pollution concentrations are therefore central to calculating removal. Extrapolation from the pollutant flux to entire trees requires estimates of leaf surface area. Field measurement such as canopy diameter and canopy height (distinguished from tree height, which includes trunk with no leaf area) can be used to estimate leaf surface area. 


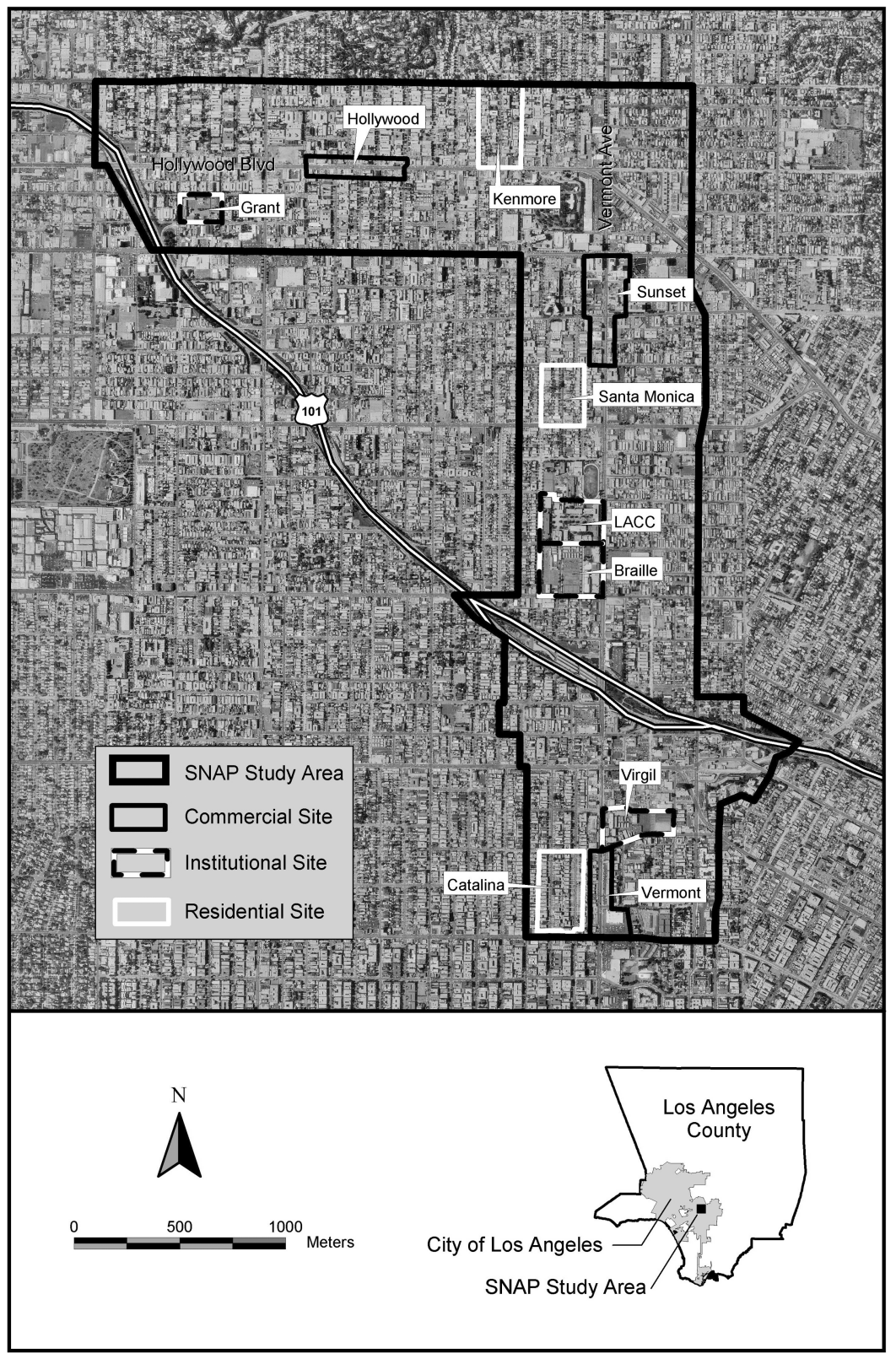

Fig. 1. Vermont/Western Station Neighborhood Area Plan (SNAP) study area with subsites by land use.

For each of the steps in calculating air pollution removal, CITYgreen offers a limited set of options. First, for existing pollution levels the user has a choice of one of eight cities (Atlanta, Austin, Baltimore, Boston, Milwaukee, New York, Philadelphia, and Seattle) or the average of these eight cities. Four of the eight cities are in the "Hot Continental 
TAble 1. Area And Cover in SAmple Subsites in SNAP Study AReA ${ }^{\mathrm{a}}$

\begin{tabular}{lcccccc}
\hline \hline Site & $\begin{array}{c}\text { Area } \\
(\text { acres })\end{array}$ & $\begin{array}{c}\text { Trees } \\
(\%)\end{array}$ & $\begin{array}{c}\text { Grass } \\
(\%)\end{array}$ & $\begin{array}{c}\text { Shrubs } \\
(\%)\end{array}$ & $\begin{array}{c}\text { Buildings } \\
(\%)\end{array}$ & $\begin{array}{c}\text { Paved } \\
(\%)\end{array}$ \\
\hline Vermont & 14.4 & 0.4 & 1.2 & 0.0 & 27.7 & 71.0 \\
Sunset & 13.5 & 2.7 & 3.7 & 1.1 & 30.0 & 64.2 \\
Hollywood & 12.8 & 2.4 & 3.2 & 0.6 & 32.4 & 62.5 \\
$\quad$ Commercial average & 13.6 & 1.8 & 2.7 & 0.6 & 30.0 & 65.9 \\
Virgil & 12.1 & 6.8 & 12.4 & 0.4 & 19.4 & 63.3 \\
LACC & 16.3 & 14.5 & 17.8 & 2.5 & 37.4 & 38.4 \\
Braille & 18.3 & 5.0 & 9.1 & 0.4 & 23.3 & 64.0 \\
Grant & 6.5 & 12.9 & 10.0 & 1.0 & 21.9 & 59.3 \\
$\quad$ Institutional average & 13.3 & 9.8 & 12.3 & 1.1 & 25.5 & 56.3 \\
Catalina & 21.4 & 4.5 & 17.4 & 3.2 & 35.3 & 45.0 \\
Santa Monica & 12.0 & 8.2 & 15.9 & 4.0 & 33.6 & 45.1 \\
Kenmore & 18.6 & 9.0 & 12.0 & 3.0 & 31.0 & 45.0 \\
$\quad$ Residential average & 17.3 & 7.2 & 15.1 & 3.4 & 33.3 & 45.0 \\
Sacramento & & & & & & \\
$\quad$ Residential average & & 27.0 & 7.0 & $\mathrm{n} / \mathrm{a}$ & 23.5 & 33.5 \\
Commercial average & & 8.0 & 11.5 & $\mathrm{n} / \mathrm{a}$ & 20.5 & 54.0 \\
& & & & & & \\
\hline
\end{tabular}

aTotals exceed $100 \%$ because coverage of tree canopy and coverage below canopy are included. For comparison, cover estimates from residential and commercial areas in Sacramento are provided (Akbari et al., 1999).

Division" of Bailey's ecoregions, and no cities represent the divisions representing the arid West, Mediterranean, or tropical climates (Bailey, 1995). This limits usefulness in the United States and worldwide. For example, a Mediterranean climate, with no freezing winter, will have very different seasonal pollution patterns than a seasonal temperate climate. As pollution data are incorporated into flux rates, those rates will be higher in Mediterranean climates because leaves are present on trees throughout most of the year. Data on pollution levels and flux rates have been collected for Los Angeles, but are not incorporated into the CITYgreen program (USDA Northeastern Forest Research Station. Syracuse, NY, unpublished data, June 4, 2001). Because of the increased pollution and longer growing season in Los Angeles, pollution removal by trees tends to be much higher for the same canopy percentage.

Second, CITYgreen uses canopy coverage as a proxy measure for leaf area. This assumes an average leaf area per canopy area, ignoring variations in canopy height, tree species, and other factors. A more accurate estimate could be obtained by using canopy height in addition to canopy diameter. This would require one additional field measurement beyond those already collected as part of the CITYgreen data collection protocol. 


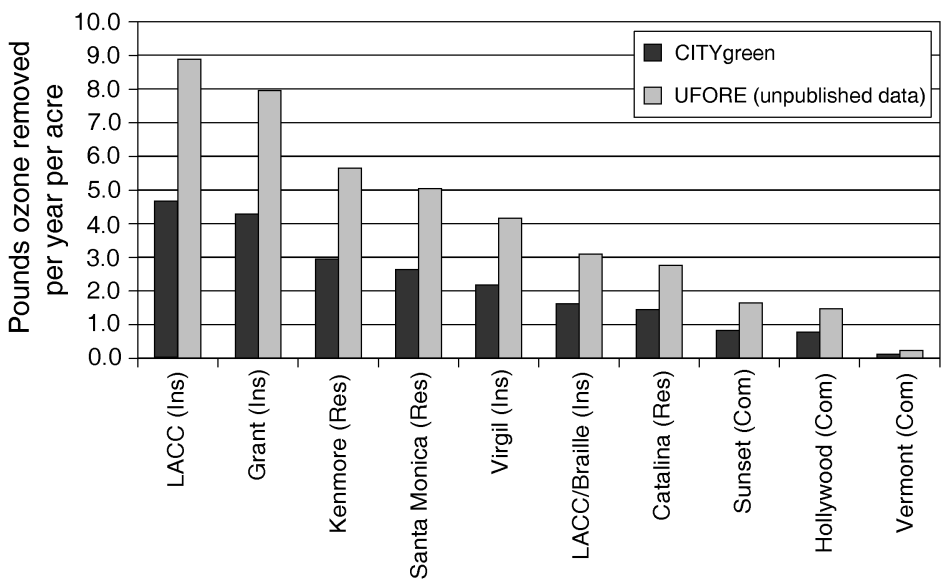

Fig. 2. Ozone removal per acre as measured by CITYgreen (average of eight cities) and UFORE (Los Angeles) pollutant flux estimates. UFORE estimates courtesy of David Nowak, USDA Forest Service, Northeast Research Station (see Nowak and Crane, 2000).

Because tree height is already measured, additional effort to record the lower extent of the canopy would add only seconds to the data collection time at each tree. Alternatively, CITYgreen could assign pollution removal by tree diameter class, which partially accounts for differences in leaf area (Nowak, 1994b). This would require additional modifications to the method used to calculate pollution removal, which constitutes our next point.

Third, CITYgreen does not actually incorporate the pollution flux model, but rather multiplies the square meters of canopy cover by a look-up value derived for one or the average of eight cities. The resulting estimates are only as good as these empirical measurements. This look-up table should (ideally) be updated as the concentration of pollution in cities changes. This look-up table approach would also have to be modified to incorporate a better estimation of leaf area as suggested above.

We used CITYgreen to calculate air pollution removal for each of the nine subsites in our study. We then calculated the value using Nowak's pollution flux data for Los Angeles (USDA Forest Service Northeastern Research Station, Syracuse, NY, unpublished data from Urban Forest Effects [UFORE] model analyses). As shown for ozone removal (Fig. 2), the results from the CITYgreen module are about 50\% of those based on the locally determined parameters from the UFORE model.

\section{Carbon Sequestration and Storage}

CITYgreen models the rate at which trees remove carbon from the atmosphere through photosynthesis (sequestration) and the total amount of carbon captured by trees over time (storage), based on research by Nowak (Rowntree and Nowak, 1991; Nowak, 1993, 1994b). This module works on a very general basis by classifying the trees at a site as either young (Type 1), older (Type 2), or with a balanced distribution (Type 3). This classification is made on the basis of the diameter breast height of trees. Each classification is associated with two multipliers (one for storage, one for sequestration), which are 
combined with site size and canopy coverage to provide estimates of carbon sequestration and storage. The CITYgreen approach can provide some surprising results, because if the overall age distribution of trees is moved from older to young by planting young trees, then the carbon storage estimate for the entire site can go down. This is not physically possible - the increased biomass of the planted trees can only add to the carbon storageand it reminds us that the carbon estimates are broad approximations.

Alternatives to the diameter class-based calculations used by CITYgreen are available. Because data on the species and diameter of each tree are collected for the CITYgreen model, carbon storage could be calculated for each tree. This process involves first calculating biomass using allometric equations from the forestry literature (Nowak, 1993). The predicted biomass can then be scaled down to account for the limiting conditions of urban growth (Nowak, 1994b). Fresh-weight biomass estimates can be converted to dry-weight measures and above-ground biomass extrapolated to whole tree estimates (Nowak, 1994b). Total sequestered carbon can then be calculated by multiplying dry-weight biomass by 0.45 (Lieth, 1963; Nowak, 1993). Calculation of sequestration could then be performed by assigning growth values to tree species (Nowak, 1994b).

This tree-by-tree method would require the development of a database of allometric equations for all species in the CITYgreen database, in addition to some reasonable generalizations for species for which no allometric equations exist. However, it would avoid the conflicting results provided by the current CITYgreen methodology. Growth rates would also need to be assembled and generalized, but many prominent genera have already been measured (Nowak, 1994b). Inclusion of this methodology in the CITYgreen program would require considerable effort, but it would provide a more precise tool to the end user. The small downside would be an increase in computer time required for calculation of module results. If CITYgreen is to be relied upon to calculate carbon storage in any actual emissions trading scheme, such an improvement will be essential.

\section{Stormwater Runoff}

The CITYgreen stormwater module is a modification of TR-55, a widely used urban hydrology model (Soil Conservation Service, 1986). It calculates the amount of runoff that will be produced based on precipitation, and the timing of the movement of the runoff through the study area. Both of these features are affected by urbanization, most commonly infiltration is reduced and travel time is decreased, which together increase the total runoff and the peak flow (i.e., more runoff is packed into a shorter time). The results are based on a series of parameters that are calculated for each hydrologically distinctive portion of the study area.

The user must calculate or estimate single values for four parameters - the percentage slope, hydrological soil group, rainfall distribution, and rainfall intensity (for a 2-year, 24-hour storm, although larger storms can be substituted for the typical storm)-in the study area. Once these values are determined, they are input in the appropriate dialog box and curve numbers (CNs) are specified for each of the main cover types found in the study area. These CNs indicates how much of a given quantity of rainfall becomes direct runoff and ranges between 0 and 100. For example, pavement has a higher $\mathrm{CN}$ than grass. The $\mathrm{CN}$ varies substantially based on the soil type underlying any specific land use. For example, a lawn may have a curve number as low as 39 on sandy soil and as high as 80 
on clay. The $\mathrm{CN}$ is also used to calculate the amount of water that can be stored by the landscape after runoff begins, and the amount of water that is retained before runoff begins (e.g., in depressions, on vegetation, and through infiltration and evaporation).

Four sets of challenges and problems confront users interested in this module. Probably, the most troubling aspect of the CITYgreen incorporation of TR-55 is evident in program implementation. The CITYgreen documentation for site digitizing and database development allows for features to overlap. Real-world trees, shrubs, grass, and buildings have overlapping footprints on the horizontal plane while they are separated in the vertical plane. Examples in the CITYgreen documentation depict overlapping feature coverages. The problem is that the stormwater module does not work properly with overlapping coverages. To obtain correct results from the stormwater calculations, coverages must be clipped so that only one coverage occurs at any given point in the CITYgreen study area. This need is trivial enough to satisfy, but the concern is that the program provides incorrect stormwater values-rather than an error message-if this condition has not been met. Unless end users are vigilant about the results derived from the program, some users may inadvertently accept and disseminate the improper results, causing confusion and potentially improper policy decisions.

Further problems may occur because of the difficulty of identifying the soil conditions in an urban study area. The county soil reports often skipped areas that were already urbanized when the fieldwork on which the reports are based was completed. The actual soil conditions may vary widely from those reported in generalized maps (like STATSGO, which is provided as the source of soils information by CITYgreen) or in situations in which the soils have experienced substantial compaction and other forms of disturbance (Schueler, 2000). The specification of ground cover in good condition on sandy, loamy sand and sandy loam textured soils with low runoff potential (hydrological soil group A) in place of ground cover in poor condition on clay soils with high runoff potential (hydrological soil group D) in Los Angeles (average precipitation of 15.14 inches for the period 1970-2000) would cause a $263 \%$ increase in the quantity of runoff estimated with the TR-55 model for example (Rawls et al., 1993).

Another potential problem with the CITYgreen stormwater module is that it cannot predict some of the additional variability that may occur because of the spatial arrangement of different cover types in a study area. The TR-55 methodology assumes that impervious areas (streets, sidewalks, rooftops, etc.) are directly connected to the drainage system. The CITYgreen stormwater module makes the same assumption and also limits the user to single values for each of the precipitation and soil parameters when the latter in particular may vary substantially across the study area. Rawls et al. (1993) and others have shown that the actual stormwater volumes and hydrographs can vary widely depending on the spatial arrangement of soils and plant cover, and this may lead to further reductions in the accuracy of model outputs when CITYgreen is applied to large study areas that incorporate substantial topographic variability (e.g., ridges, sideslopes, footslopes, valley bottoms, etc.).

The final problem encountered with the application of this module in the Vermont/ Western study area concerns the estimation of dollar benefits and costs. The CITYgreen manual suggests contacting local city planning or public works departments to determine the cost of building retention ponds, additional stormwater management facilities, and treatment facilities to accommodate additional stormwater runoff. This approach does not 
apply to long-established, densely settled urban areas like our study area, where the goal might be to estimate the savings that could accrue from enhanced stormwater retention. These savings are very difficult to estimate and would accrue only if additional pressures were exerted on stormwater management facilities from increased runoff in other areas, or if concerns about stormwater quality at downstream locations (outfalls, estuaries, beaches, etc.) were considered.

In most CITYgreen analyses, reduction of stormwater runoff accounts for over $95 \%$ of the economic benefits of greening. While this result may be correct, several factors suggest that this proportion may be artificially inflated. First, as discussed above, the cost of stormwater capacity may not be avoided even with substantial tree cover, either because the infrastructure already exists, or runoff occurs during periods when trees are not in leaf. While this is not a significant consideration for Los Angeles, other cities may experience maximum runoff from snowmelt upon which trees have little effect. Second, the economic value of other "nature's services," such as removal of air pollution, may be underestimated. This is likely for air pollution because market valuation methods do not incorporate the costs to human health or the natural environment. The cost to industry to remove a ton of pollution - the market value-may be far less than the economic benefit of removing the pollution to human health.

\section{Energy Conservation}

The energy conservation model calculates energy savings for direct shading of buildings (especially air conditioners and windows). Shade from trees reduces the amount of energy needed to cool structures in the summer, while windbreaks created by trees reduce heating costs in winter (McPherson, 1994). In the summer the increased shade offsets the decreased cooling from lessened air circulation caused by trees (Huang et al., 1987). The research in this area has largely been conducted on small residential buildings (Huang et al., 1987; Akbari et al., 1993). These studies model and measure cooling benefits for structures of less than 2,000 square feet and one or two stories. While cooling benefits of trees near larger structures are certainly realized, current research does not provide guidance for calculating these benefits (Jones and Stokes Associates, 1998). Larger structures have a much larger volume-to-surface-area ratio, which would tend to decrease cooling benefits, but can also have larger windows that can be shaded on many floors, which would increase cooling benefits.

The inability to calculate energy savings for structures larger than one or two stories poses a substantial impediment to the analysis of densely populated urban neighborhoods. This is not a failing of CITYgreen, but represents the current state of research.

\section{Cool Roofs}

CITYgreen includes a module to evaluate the energy savings from lightly colored roofs that increase building albedo. This module too is designed only for use with single-family residences, specifically one or two stories tall, with asphalt shingle roofs. The benefits of more reflective roofs are significant, and perhaps equal benefits from shading by trees. Because our study area did not include structures suitable for this analysis, we do not consider it further. 


\section{Wildlife Benefits}

The analysis in this module of the CITYgreen program consists of assigning a wildlife rating to trees based on their ability to provide food, shelter, or nesting sites. The scores are then mapped to show the distribution of these resources across the study site. The scores are generated from secondary literature and are provided for only 100 species of trees. This approach does not allow for analysis of the relevant benefits of species in different regions of the country, eliminating any evaluation of the appropriateness of the tree cover to the surrounding natural landscape.

An ample literature on the ecology of urban areas exists to develop a more sophisticated analysis of wildlife benefits from the urban forest. In doing so, one must make the critical distinction of whether all wildlife is desired, or whether measurement should be geared toward provision of habitat for native species. Because non-native species thrive in cities already, with the same suite of birds found in cities across entire continents, emphasis on native species would provide a more useful conservation tool.

In this respect, a first test of wildlife value is whether the plant species in the landscape are native. CITYgreen provides for collection of species data on all trees, and a notation to indicate whether species are native or not would be trivial to add. Species data are not collected about shrubs, nor would it be practical to expect this of analysts. Grasslands also have no species data but are presumed to all be exotic cultivars. The presence of native species is important as bird habitat and for native insects such as butterflies. Even with the limited information gathered for CITYgreen analysis, different regions of the county should be assessed according to the natural landscape on which the city or suburb has been established.

We propose an index approach to wildlife benefits, wherein the study site is given a wildlife suitability index based on the percent cover of certain features, weighted according to their value. For the Mediterranean climate of Southern California an index might present a weighted sum of cover variables, whereby native trees and shrub cover is weighted highest, while grass and exotic trees receive lesser weight and palm trees receive no weight. This scheme incorporates elements of a recent Spanish study in which bird species richness in Madrid was positively correlated with a variable composed of percentage grass cover, percentage shrub cover, number of species of shrubs, and number of species of trees (Fernandez-Juricic, 2000). Such a scheme could be validated with field studies, and be tailored by ecoregion, to best indicate the degree to which the vegetation incorporates elements that will be attractive to native wildlife. In our opinion, almost any algorithm would provide greater information for planning than the method currently used by CITYgreen by allowing quantitative comparisons among sites and scenarios.

\section{Tree Growth Model}

CITYgreen's tree growth model is used to forecast the growth of trees in a study area into the future, and thereby allows calculation of future environmental benefits. The model calculates growth based on the initial diameter at breast height and tree height, making these measurements critical to the analysis. Constant growth rates are applied for trees within each of three classes (slow growing, medium growing, and fast growing). American Forests determined the growth factors based on measurements from many tree 
specimens. This research has not been published in the peer-reviewed literature, although it would constitute a valuable addition. Many species in the CITYgreen database do not have growth rates, nor are many species found in the western region of the country in the database. If the growth model developed by American Forests is to gain academic acceptance, the growth model must be published, and account for regional differences in growth rate. It would be a benefit to users if American Forests established an online library of species parameters to exchange information about species characteristics among users and to provide the underlying data that support the growth model. Such information would be available on an "as-is" basis, and vetted for potential inclusion in future versions of the program.

\section{CONCLUSION}

CITYgreen is a tool to help guide policy on urban green infrastructure. The program has prompted significant attention to the question of urban forest loss, and led to policy changes in several regions of the country. The program guides the collection of, and easily maintains a substantial amount of field data that allow analysis of "nature's services" in urban and suburban landscapes.

Its obvious benefits and successes notwithstanding, CITYgreen still contains several important limitations. The program is better suited to analysis of suburban morphology than higher density, central-city areas. The energy savings modules apply only to single-family dwellings, which are virtually absent in heavily-populated urban neighborhoods, industrial areas, or downtowns. Ironically, although the tool illustrates the benefits of maintaining current vegetative cover, it seems better suited to evaluate the morphologies of suburban sprawl single family residences with newly planted trees and lawn. One example of this is that the tree growth model seems to work well on young trees, but models unrealistically large future tree sizes for mature trees. Indeed, one of the example applications of CITYgreen is to show the benefits of trees in new developments.

Even though CITYgreen is not marketed as a scientific tool, the best available methods are not incorporated into estimates of air pollution removal or carbon storage and sequestration. For air pollution removal, the assumptions required by the program may result in a 50\% underestimate in pollutants removed, which may make the difference between determining that a program is economically feasible.

American Forests, through the promotion of CITYgreen, has been successful in raising the visibility of urban forestry and the economic consequences of forest loss. However, even as the public relations aspect has excelled, CITYgreen could be improved to provide a more accurate accounting of the role of urban forests and greenspace as "nature's services."

\section{REFERENCES}

Akbari, H. S., Bretz, S. E., Hanford, J. W., Kurn, D. M., Fishman, B. L., Taha, H. G., and Bos., W., 1993, Monitoring Peak Power and Cooling Energy Savings of Shade Trees and White Surfaces in the Sacramento Municipal Utility District (SMUD) Service Area: Data Analysis, Simulations, and Results. Berkeley, CA: Lawrence Livermore Laboratory. 
Akbari, H. S., Rose, L. S., and Taha, H., 1999, Characterizing the Fabric of the Urban Environment: A Case Study of Sacramento, California. Berkeley, CA: Lawrence Livermore Laboratory.

American Forests, 1998, Puget Sound Ecological Analysis. Washington, DC: American Forests.

American Forests, 1999, Regional Ecosystem Analysis: Chesapeake Bay Region and the Baltimore-Washington Corridor. Washington, DC: American Forests.

American Forests, 2000a, CITYgreen 4.0 User Manual. Washington, DC: American Forests.

American Forests, 2000b, Urban Ecosystem Analysis for the Houston Gulf Coast Region. Washington, DC: American Forests.

Bailey, R. G., 1995, Descriptions of the Ecoregions of the United States. Washington, DC: U.S. Department of Agriculture, Forest Service.

Baldocchi, D. D., 1988, A multi-layer model for estimating sulfur dioxide deposition to a deciduous oak forest canopy. Atmospheric Environment, Vol. 22, 869-884.

Costanza, R., D'arge, R., De Groot, S., Farber, M., Grasson, B., Hannon, K., Limburg, S., Naeem, R., O'Neill, V., and Paruelo, J., 1997, The value of the world's ecosystem services and natural capital. Nature, Vol. 387, 253-260.

Cranz, G., 1983, The Politics of Park Design: A History of Urban Parks in America. Cambridge, MA: Massachusetts Institute of Technology Press.

Daily, G., editor, 1997, Nature's Services: Societal dependence on Natural Ecosystems. Washington, DC: Island.

Fernandez-Juricic, E., 2000, Avifaunal use of wooded streets in an urban landscape. Conservation Biology, Vol. 14, 513-521.

Harnik, P., 2000, Inside City Parks. Washington, DC: ULI-The Urban Land Institute, in cooperation with the Trust for Public Land.

Huang, Y., Akbari, H. S., Taha, H., and Rosenfeld, A. H., 1987, The potential of vegetation in reducing summer cooling loads in residential building. Journal of Climate and Applied Meteorology, Vol. 26, 1103-1116.

Jones and Stokes Associates, 1998, Product Specification for the Transagency Resources for Economic and Environmental Sustainablilty Project. Sacramento, CA: Prepared for TreePoeple, Beverly Hills, CA.

Lang, J. T., 1998, Benefits from urban forestry. The Military Engineer, Vol., 33-34.

Lieth, H., 1963, The role of vegetation in the carbon dioxide content of the atmosphere. Journal of Geophysical Research, Vol. 68, 3887-3898.

McPherson, E. G., 1994, Energy-saving potential of trees in Chicago. In E. G. McPherson, D. J. Nowak, and R. A. Rowntree, editors, Chicago's Urban Forest Ecosystem: Results of the Chicago Urban Forest Climate Project, General Technical Report NE-186. Radnor, PA: USDA Forest Service.

McPherson, E. G., 1997, Benefit-Cost Analysis of LADWP's School Tree Planting Program in Los Angeles. Davis, CA: Western Center for Urban Forest Research and Education.

McPherson, E. G., Nowak, D. J., and Rowntree, R. A., editors, 1994, Chicago's Urban Forest Ecosystem: Results of the Chicago Urban Forest Climate Project, General Technical Report NE-186. Radnor, PA: U.S. Department of Agriculture, Forest Service, Northeastern Forest Experiment Station. 
McPherson, E. G., Simpson, J. R., Peper, J., and Xiao, Q., 1999, Benefit-cost analysis of Modesto's municipal urban forest. Journal of Arboriculture, Vol. 25, 235-248.

Miller, L., 1995, GIS branches into urban forestry. American City \& County, Vol. 110, 35.

Nowak, D. J., 1993, Atmospheric carbon reduction by urban trees. Journal of Environmental Management, Vol. 37, 207-217.

Nowak, D. J., 1994a, Air pollution removal by Chicago's urban forest. In E. G. McPherson, D. J. Nowak, and R. A. Rowntree, editors, Chicago's Urban Forest Ecosystem: Results of the Chicago Urban Forest Climate Project, General Technical Report NE-186. Radnor, PA: USDA Forest Service.

Nowak, D. J., 1994b, Atmospheric carbon dioxide reduction by Chicago's urban forest. In E. G. McPherson, D. J. Nowak, and R. A. Rowntree, editors, Chicago's Urban Forest Ecosystem: Results of the Chicago Urban Forest Climate Project, General Technical Report NE-186. Radnor, PA: USDA Forest Service.

Nowak, D. J. and Crane, D. E., 2000, The Urban Forest Effects (UFORE) Model: Quantifying urban forest structure and functions. In Hansen, M. and T. Burk, editors, Integrated Tools for Natural Resource Inventories in the 21 st century, IUFRO Conference. St. Paul, MN: U.S. Department of Agriculture, Forest Service, North Central Research Station.

Nowak, D. J. and McPherson, E. G., 1993, Quantifying the impact of trees: The Chicago Urban Forest Climate Project. Unasylva, Vol. 173, 39-44.

Pacific Meridian Resources, 2000, Quantifying the Value of Urban Forest Land in Macon, Georgia. Macon, GA: Pacific Meridian Resources.

Rawls, W. J., Ahuja, L. R., Brakensiek, D. L., and Shirmohammadi, A., 1993, Infiltration and soil water movement. In D. R. Maidment, editor, Handbook of Hydrology. New York, NY: McGraw-Hill.

Rowntree, R. A. and Nowak, D. J., 1991, Quantifying the role of urban forests in removing atmospheric carbon dioxide. Journal of Arboriculture, Vol. 17, 269-275.

Schueler, T., 2000, The Compaction of Urban Soils. The Practice of Watershed Protection. Ellicott City, MD: Center for Watershed Protection.

Soil Conservation Service, 1986, Urban Hydrology for Small Watersheds, Technical Release 55. Washington, DC: United States Department of Agriculture.

Taha, H., 1996, Modeling the impacts of large-scale albedo changes on ozone air quality in the South Coast Air Basin. Atmospheric Environment, Vol. 30, 3423-3430.

Tuma, R., 2001, Money: The New Face of Ecology. Retrieved March 16, 2001 from news.bmn.com/hmsbeagle/98/notes/feature2

Tyrvainen, L. and A. Miettinen, 2000, Property prices and urban forest amenities. Journal of Environmental Economics and Management, Vol. 39, 205-223. 